\title{
PLANEJAMENTO PARA A PARTICIPAÇÃO DE ALUNOS DOS ÚlTIMOS PERIODOS DO CICLO PROFISSIONAL DE ENFERMAGEM NA IDENTIFICAÇĀO E TREINAMENTO DE PARTEIRAS LEIGAS DE UMA COMUNIDADE
}

* Celina Maria Araújo Tavares

\begin{tabular}{l|l|} 
& RBEn/08 \\
\hline
\end{tabular}

TAVARES, C.M.A. - Planejamento para a participação de alunos dos últimos períodos do ciclo profissional de enfermagem na identificação e treinamento de parteiras leigas de uma comunidade. Rev. Bras. Enf.; DF, 32:89-120, 1979.

\section{DEFINIÇÃO DO PROBLEMA}

Uma ação conjunta entre comunidade, instituiçōes de saúde e estudantes de enfermagem proporcionaria melhor assistência no parto domicillar?

\section{JUSTIFICATIVA}

Sabendo-se que as instituiçōes que prestam assistência à parturiante sāo deficientes, tanto em quantidade quanto em qualidade e, partindo-se do pressuposto que se houvesse conscientização da comunidade para uma maior utillzação dessas instituiçóes, provavelmente seria impossivel o atendimento de todas as parturientes com estes recursos. Vemos então que a cobertura da populacão de mulheres durante o parto, bem poderia ser feita a nivel de atençāo primária, ou seja, utilizando os próprios recursos da comunidade.
No intuito de conseguir trabalhar com a comunidade de maneira profunda, realizando trocas culturais e comportamentais, resolvemos dirigir nosso planejamento de atividades para elementos chaves, quais sejam, as partelras leigas. Estes elementos funcionam como líderes, exercendo grande domínio e desfrutando de grande prestígio na comunidade onde vivem. Através da identificaçāo, aproximaçāo e autêntico interesse pelo ensino-aprendizagem e treinamento destas, espera-se que os resultados obtidos, em termos de comunidade, sejam muito mais abrangentez.

- Docente de Enfermagem da U.F.M.T. Aluna do Curso de Especialdosăa em Metodologia do Ensino e de Assistencia de Enfermagem UFGo - 1978. 
TAVARES, C.M.A. - Planejamento para a participação de alunos dos últimos períodos do ciclo profissional de enfermagem na identificaçāo e treinamento de parteiras leigas de uma comunidade. Rev. Bras. Enf.; DF, 32:89-120, 1979.

De modo a favorecer tanto a comunidade como a aprendizagem e troca cultural, importante nos parece tentar uma integração da universidade, através de seus alunos, com essas comunidades, em um planejamento integrado junto a grupos comunitários de sorte. a permitir a identificação e treinamentos de parteiras e māes em uma área. Para isto, teremos que considerar de maneira especial três enfoques: atençāo primária de saúde, a comunidade e a participação de alunos de enfermagem em trabalhos diretos com a comunidade.

\section{1 - Atenção Primária de Saúde}

Um dos grandes problemas atuais da humanidade é o grande número de pessoas que estāo fora do alcance dos sistemas formais de assistência à saúde, apesar destes estarem se desenvolvendo numa tentativa frustrada de abranger toda a população.

Este é um problema que vem preocupando a todos os envolvidos nesta área de tal forma que, na IV Reunião Especial dos Ministros de Saúde das Américas (16), realizada em 26 e 27/ $09 / 77$, em Washington, foram confirmados os propósitos de "intensificar os esforços e aumentar os recursos para acelerar os processos de extensāo da cobertura de Serviços de Saúde a toda a população". Visando este atendimento global, é indispensável buscar outros procedimentos, neste caso a atençāo primária de Saúde. Na Conferência Internacional (15) sobre atençāo primária de saúde realizada na Rússia no periodo de $06-12 / 09 / 78$, esta foi conceituada como: "um meio prático para colocar ao alcance de todos os individuos e famílias das comunidades a assistência de saúde indispensável, de forma aceitável e proporcional a seus re- cursos, e com sua plena participação". Para isso engloba os fatores sociais e de desenvolvimento que influem no funcionamento do sistema de saúde.

E indispensável, portanto, a participação de representantes da comunidade no planejamento e execução dos programas de desenvolvimento, pois estes estão vivendo as difículdades, sentindo as necessidades e desfrutando de interesses comuns.

A assistência materno-infantil é uma área muito apropriada ao trabalho do sistema formal junto aos sistemas não formais de saúde praticados pelas comunidades.

"A confiança no próprio esforço e a consciência social são fatores chaves no progresso humano". (18)

Baseados nesses conhecimento da comunidade sobre sua própria situação, o primeiro passo do sistema formal será a identificação dos líderes, no caso de assistência materno-infantil principalmente, as parteiras leigas, que funcíonarāo como agentes de saúde propiciando o desenvolvimento pessoal e coletivo. Ao sistema de saúde, no caso com a participação ativa de alunos de enfermagem, caberá discutir e desenvolver o treinamento, assessoramento e controle às pessoas que já prestam assistência nāo formal às comunidades. assim como a troca de informaçōes claras sobre as vantagens e desvantagens das atividades propostas e seus custos relativos.

Delimitadas as atividades de cada um dentro do sistema de assistência primária, parte-se em conjunto para, a avaliação da situação, a definição dos problemas, a determinação das prioridades e o planejamento.

A execução das atividades deve ser revista continuamente, para que estas se desenvolvam de acordo com os objetivos traçados, para facilitar a identi- 
TAVARES, C.M.A. - Planejamento para a participação de alunos dos últimas períodos do ciclo profissional de enfermagem na identificação e treinamento de parteiras leigas de uma comunidade. Rev. Bras. Enf.; DF, $32: 89-120,1979$.

ficaçāo e listagem das dificuldades e para o reajuste das atividades quando necessário.

\section{$2.2-A$ Comunidade}

O grupo materno-infantil considerado em seu sentido mais amplo, abrange cerca de $70,98 \%$ da população brasileira. Frente à importância, biológica e sócio-econômica, deste contingente populacional, o Ministério da Saúde destaca-o como "de" prioridade para efeito das açōes integradas de saúde, de interesse coletivo". (11)

Visando a elevação do nível de saúde deste grupo foi traçado o Programa de Saúde Materno-Infantil, que integra a Política de Saúde MaternoInfantil prevista no artigo $10^{\circ}$ da Lei n. ${ }^{\circ} 6.229 / 75$, cujo objetivo central é a redução da morbidade e mortalidade do grupo materno-infantil. (10)

A fim de alcançar este objetivo estão propostas, no II Plano Nacional de Desenvolvimento, as seguintes metas (11), para o grupo materno:

- Cobertura de $50 \%$ da população de gestantes;

- Cobertura de 50\% na assistência técnica ao parto;

- Cobertura de $20 \%$ na assistência ao puerpério.

Incluindo no Programa de Saúde Materno-Infantil está o subprograma de Assistência Materno (11), atendendo:

- A gestação através da assistência pré-natal precoce, contínua e regular;

- Ao parto através de Unidades de Saúde que proporcionem assistência ou supervisāo técnica ao parto domiciliar;
- Ao puerpério através de supervisão ginecológica à mulher e, assistência e proteção ao recémnascido.

Pode-se assegurar, pelo depoimento de autoridades sanitárias e observaçāo das estatísticas vitais, que é grande $o$ número de gestantes atendidas em seu domicílio pela parteira leiga, que pouco ou nenhum preparo técnico-formal tem para dar uma contribuição mais efetiva. Esta característica é muito encontrada atualmente, nas comunidades economicamente menos desenvolvidas. Nas regiōes mais desenvolvidas a responsabilidade da gestante está a cargo do médico ou da enfermeira obstétrica.

FREDDI (3) diz que - "a responsabilidade da enfermeira obstétrica abrange o treinamento do pessoal em serviço, cabendo-lhe, ainda, o treinamento e a supervisāo de "curiosas". A tutela das "curiosas tradicionais" é ainda necessária em nosso meio, pois estas nāo podem ser substituídas totalmente por enfermeiras obstétricas, como seria ideal".

\section{3 - A Participação de Alunos de Enfermagem}

Por que a participaçāo de alunos dos últimos períodos do curso de graduação em enfermagem?

Um dos principais objetivos estabelecidos no Plano Decenal de Saúde (Santiago, 1972) foi "a extensāo dos serviços de saúde, de maneira que ao final da década sejam acessíveis a toda a população do Hemisfério" (17). A enfermeira pode ser o ponto chave para que este objetivo seja alcançado. Como integrante da equipe deve encarar salde nāo em termos individuais, e sim considerando a comunidade como um todo, reconhecendo que as açōes nâo 
TAVARES, C.M.A. - Planejamento para a participação de alunos dos últimos periodos do ciclo profissional de enfermagem na identificaçáo e treinamento de parteiras leigas de uma comunidade. Rev. Bras. Enf.; DF, $32: 89-120,1979$.

devem partir só do setor de saúde, mas de uma ação conjunta com outros setores. Certamente se aproveitado todo o potencial de formação dos enfermeiros, grande parte da extensão de cobertura dos Serviços de Saúde, particularmente no que se refere à assistência materno-infantil, poderia ser entregue à responsabilidade desse pro. fissional.

Nesse trabalho ousamos propor que seja modificado o enfoque do ensino de enfermagem em nossa Universidade, por sentir a necessidade de que o aluno gradue-se com uma visão ampla sobre enfermagem e esteja preparado para desenvolver atividades de maneira a responsabilizar-se socialmente pela elevaçāo do nível de saúde da população. Para conseguir isso ele terá que encarar a comunidade como cliente que tem o direito de decidir sobre o seu processo de desenvolvimento e participar de modo decisivo na obtençāo e manutençāo da saúde. Nesse caso o prineípio maior é o da ação coletiva, antes mesmo que o da ação individual.

E o papel da enfermeira neste novo enfoque será desempenhado ao incluir as seguintes atividades:

- "Diagnosticar o nível de saúde do indivíduo e da comunidade como um todo;

- Tomar decisōes junto aos representantes da comunidade em situações que exijam discernimento e execução das soluçóes pertinentes;

- Participar da capacitação do indivíduo e da comunidade para identificar e satisfazer suas necessidades;

- Avaliar junto com os usuários o efeito que as ações de saúde têm sobre o individuo, grupo e comuniajade". (17)
Considerando as recomendaçōes do Grupo Setorial de Saúde, DAU/MEC, em Indicadores de Qualidade para Cursos de Graduação em Enfermagem (8), um dos indicadores destaca a "artículação entre os programas dos serviços de saúde e os de ensino de enfermagem" a fím de tornar mais autêntica e assegurada a introduçāo dos docentes e discentes na força de trabalho, bem como mais frontalmente verdadeiro o encontro do ensino-aprendizagem com a situação da clientela.

Estão indicados alunos dos últimos períodos do curso de graduaçāo, observando que:

- Já cursaram o ciclo básico e parte do ciclo profissional, incluindo Enfermagem em doenças transmissiveis;

- Já cursaram ou estão cursando Enfermagem Materno-Infantil;

- Estão ou estarāo cursando Enfermagem em Saúde Pública.

Uma ação conjunta entre o corpo discente e o pessoal dos serviços de saúde, irá desenvolver modelos de assistêncía sanitária, que envolvam a participação ativa da comunidade na resolução das suas necessidades de saúde e propiciarāo aprendizagem apropriada para os estudantes ao "incorporar no ensino conceitos e experiências de aprendízagem em Enfermagem dirigidos à comunidade como um todo". (17)

Este trabalho possibilitará ao estudante fazer: um diagnóstico de saúde da comunidade, a identificaçāo e atenção a grupos de alto risco e a avaliação da atenção de enfermagem à clientela.

Pensamos também na interação da enfermagem com outros integrantes da equipe de saúde deixando assim em aberto a ínclusão de outros niveis profissionais atuando em conjunto dentro 
TAVARES, C.M.A. - Planejamento para a participação de alunos dos últimos períodos do ciclo profissional de enfermagem na identificação e treinamento de parteiras leigas de uma comunidade. Rev. Bras. Enf.; DF, 32:89-120, 1979.

deste planejamento. Isto favoreceria nāo só a integração Universidade-Comunidade como também a integraçāo en equipes profissionais a partir da formação na própria Universidade, onde todos trabalharāo em conjunto para o fortalecimento de suas açōes e para o surgimento de um respeito mútuo nas atividades de cada um, para a efetivaçāo de utilidade social de todas as profissōes da saúde.

\section{OBJETIVOS}

Um projeto dessa natureza visa:

- Reduzir a morbilidade e a mortalidade materna e neo-natal.

- Identificar, treinar e controlar parteiras leigas de uma regiāo, reconhecendo-as como agentes de saúde, em partos domiciliares, sob supervisāo e apoio técnico da enfermagem.

- Integrar as atividades de estudantes de enfermagem com programas de atenção primária de saúde, na área materno-infantil.

- Incluir no currículo, experiências de aprendizagem que permitam ao estudante incorporar em suas açōes de enfermagem, a identificação precoce de grupos de alto risco perinatal na comunidade.

- Modificar o enfoque do ensino, em enfermagem, de saúde individualizada para saúde comunitária.

- Incorporar nos conjuntos de atividades técnicas e éticas pertinentes à educaçāo a importância dos elementos culturais e das trocas que devem ocorrer para solidificar e aprofundar os conhecimentos de Saúde.

\section{DEFINIÇÃO DE TERMOS}

\section{1 - Agentes de Saride}

Individuo que, possui um papel de liderança na comunidade e, será treinado para promover seu desenvolvimento e o desenvolvimento da comunidade.

\section{2-Alto Risco}

Sāo patologias ou condiçōes físiológicas que podem causar danos para mãe e filho.

\section{3 - Atenção Primária}

“E um meio prático para colocar ao alcance de todos os indivíauos e familias das comunidades, assistência de saúde indispensável, de forma aceitável e proporcional a seus recursos, e com sua plena participação". (14)

\section{4- Comunidade}

Organizaçāo social composta de pessoas que compartilham, em distintos graus, de características, interesses $e$ aspiraçōes politicas, econômicas, sociais e culturais.

\section{5 - Controle}

Conjunto de medidas propostas para identificar as fases de desenvolvimento de um fenômeno.

\section{6 - "Curiosas"}

Ver parteira leiga.

\section{7 - Parteira Leiga}

Mulher, sem preparo teórico ou prático, que graças à sua experiência e/ou aos laços de parentesco ou amizade que a une às familias, realiza partos nos domicílios. 
TAVARES, C.M.A. - Planejamento para a participação de alunos dos últimos períodos do ciclo profissional de enfermagem na identificação e treinamento de parteiras Ieigas de uma comunidade. Rev. Bras. Enf.; DF, 32:89-120, 1979.

\section{8 - Perinatal}

Refere-se à mulher e à criança no período do parto.

\section{9 - Treinamento}

Curso de pequena duração, que tem como finalidade desenvolver habilidades em uma determinada área.

\subsection{0 - Unidade de Saúde}

Estabelecimento de saúde destinado a prestar assistência médico-sanitária a uma população, em área geográfica definida, sem internação de pacientes.

\subsection{1 - Enfermeira Obstétrica}

Profissional de nível universitário que prossegue o curso além de enfermeiro geral, optando pela habilitação específica em enfermeiro obstetra ou obstetriz.

\subsection{2 - Enfermeiro Geral}

Profissional de nível universitário que tem o seu curso de graduação coin Cíclo Básico e Cíclo Profissional obedecido o Currículo Mínimo da Resolução n. ${ }^{\circ}$ 4/72, apenas não optando por qualquer habilitaçāo específica. Corresponde ao título de Enfermeiro Geral ou como chamam alguns Enfermeiro Generalista.

\section{DESENVOLVIMENTO DO PLANEJAMENTO}

Dissemos antes que a parteira leiga é uma líder natural na sua comunidade, que bem deve ser reconhecida como agente de saúde, sob a supervisão, e apoio da enfermeira.

Urge, portanto, lançar medidas próprias para: sua identificação na comunidade; oferecer-lhes um treinamento que objetive melhorar a prática de seus serviços em conhecimentos e técnicas para que prestem um serviço domiciliar melhor, contribuindo assim para a diminuição dos coeficientes de morbimortalidade perinatal e, promova a ligação das parteiras aos serviços de saúde para controle e orientação continua de suas atividades.

Descreveremos a seguir um modelú de planejamento para identificação, treinamento e controle de parteiras leigaz. Este está dividido em etapas, assim dispostas:

\section{1 - Primeira Eetapa - Análise da Comunidade}

Para realizar uma açāo de saúde. com a participação comunitária, é necessário fazer uma análise para conhecer a comunidade, seu modo de vida e o modo de pensar dos seus habitantes. Assim saberemos se a ação que pretendemos programar é uma resposta às suas necessidades.

Em primeiro lugar devem ser coletados dados sobre a comunidade, através de um formulário abrangendo:

- Características geográficas;

- Características populacionais;

- Características sócio-econômicas;

- Características ambientais;

- Características dos meios de comunicação;

- Características de saúde.

Coletados, os dados seriam analisados principalmente visando verificar a disponibilidade dos recursos que poderão ser utilizados no desenvolvimento do programa.

Os problemas de saúde seriam observados a partir da estatística vital e. particularmente no nosso caso, a morbi- 
TAVARES, C.M.A. - Planejamento para a participação de alunos dos últimos períodos do ciclo profissional de enfermagem na identificação e treinamento de parteiras leigas de uma comunidade. Rev. Bras. Enf.; DF, 32:89-120, 1978.

mortalidade perinatal que serviria de referência para a implementação do programa.

Os líderes, grupos e instituiçōes ne.. cessários na dinâmica do trabalho seriam identificados para uma conscientização e mobilização posterior. Seriam verificados:

- Número de parteiras da área;

- Suas condiçōes de trabalho;

- Frequiência de complicaçōes;

- Tipo de clientela atendida;

- Número de gestantes da área;

- Gestantes que freqüentam serviços de pré-natal;

- Número de instituiçōes de saúcie da área;

- Tipo de assistência prestada;

- Capacidade de atendimento;

- Outros.

\section{2 - Segunda Etapa - Entrosa- mento com as Instituições de saúde.}

Para estimar, os recursos materiais e humanos de saúde, envolvidos na implementação do programa, é necessário o entrosamento com as instituiçōes de saúde da área. Estas deverāo ser motivadas e mobilizadas no sentido de contribuir com assessoramento ao programa, de modo que sirvam de base para a sua implantação. Isto se faz necessário principalmente porque o programa será desenvolvido com alunos, e temos que lembrar que as atividades escolares abrangem todo o ano-calendário universitário, ficando assim em descoberto alguns meses. Se pensarmos em termos de saúde da comunidade, veremos que não é válido ter programas desenvolvidos em períodos cíclicos. Se estamos propondo treinamento e controle de parteiras leigas, o melhor modo de tornar efetivo o programa é estarmos presentes continuamente.

Daí a importância de, em programass dessa natureza, promover a integração entre Comunidade, Unidades de Saúde Pública, Unidades Hospitalares e Universidade para a melhoria da assistência ao parto. Estas estarão ligadas diretamente à parteira, que continuará rea lizando as açōes para elevar o padrão de assistência ao parto na comunidade, e ao lado disso ter livre acesso ao sis.tema formal recorrendo ao mesmo não somente após às complicações já instaladas, mas sobretudo no clima de confiança e apoio técnico-científico e ético que deve existir no reconhecimento da co-existência dos dois sistemas, forma! e não formal. Aí é que deve ser entendido o enfermeiro e/ou o estudante de Enfermagem como o intérprete do sistema não formal junto ao sistema formal e estabelecer a relação de ajuàa reciproca face aos fatos culturais e à evolução científica, cumprindo um papel de analista ao tempo que equilibrador entre as situaçōes que devem ser preservadas porque não agridem à saúde $e$ as que têm que ser discutidas $e$ resolvidas junto à comunidade porque representam riscos à vida. Por sua vez, uma responsabilidade torna-se preponderante ao se tratar sobre saúde coletiva em trabalhos dessa natureza, qual seja a de reconhecer que o modo próprio de viver de cada comunidade representa o elemento vivo de alimentação do sistema formal de prestação de serviços que a ela se dirige. 
TAVARES, C.M.A. - Planejamento para a participação de alunos dos últimos períodos do ciclo profissional de enfermagem na identificação e treinamento de parteiras leigas de uma comunidade. Rev. Bras. Enf.; DF, 32:89-120, 1978.

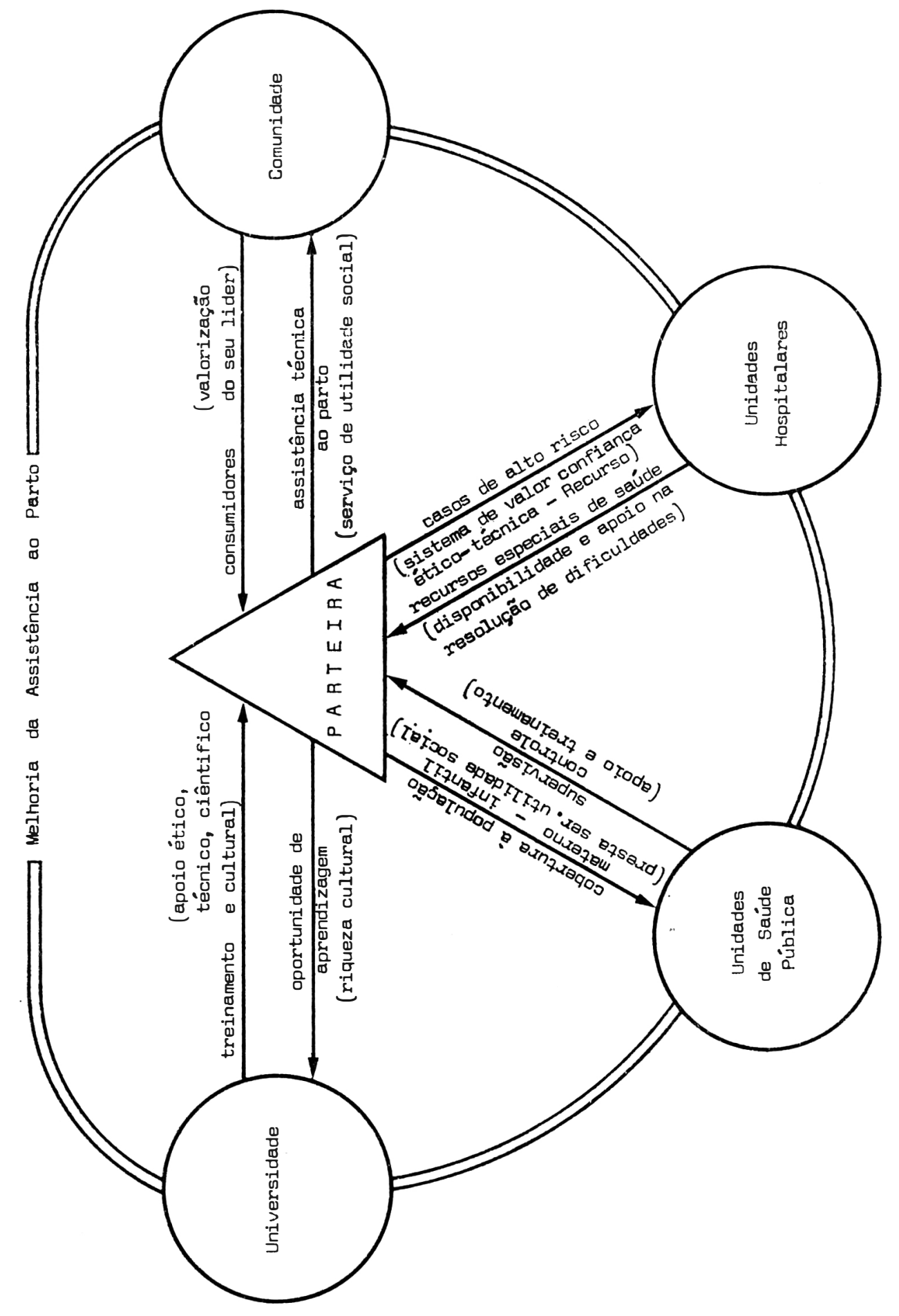


TAVARES, C.M.A. - Planejamento para a participação de alunos dos últimos períodos d) ciclo profissional de enfermagem na identificação e treinamento de parteiras leigas de uma comunidade. Rev. Bras. Enf.; DF, 32:89-120, 1979.

\section{3 - Terceira Eetapa - Treinamento dos Alunos das Disciplinas Materno- Infantil e saúde Pública.}

Com a participação de alunos das dissiplinas Materno-Infantil e Saúde Pública estaremos propiciando que seja dadis um enfoque duplo para o problema.

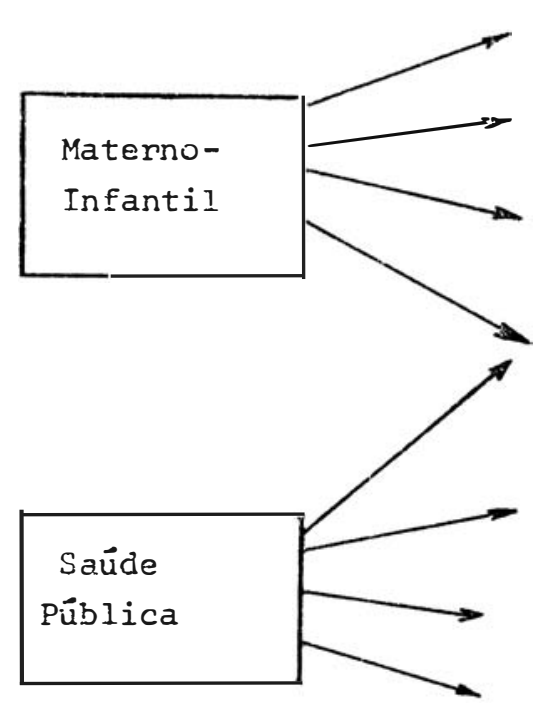

diminuir morbi-mortalidade perinatal.

melhorar a assistência técnica ao parto.

desenvolver habilidade e destreza.

proporcionar a criança que irá nascer, condições

de sobrevivência e desenvolvimento melhores.

encarar a comunidade como paciente.

utilizar os recursos da própria comunidade.

abranger maior número de pessoas nas ações de saúde.

Para a nartícipaçāo do aluno nesse planejamento é necessário:

- Embasamento teórico-prático na disciplina Enfermagem Obstétrica:

- Conhecimento do programa do curso;

- Habilidade e destreza na assistência ao parto;

- Entrosamento prévio com a Unidade Sanitária e demais instituições de saúde participantes;

- Interação com a comunidade em que vai atuar.

\section{4 - Quarta Etapa - Planejamen- to do Programa}

\subsection{1 - Cadastramento}

As parteiras leigas seriam cadastradas de acordo com a área de atuação das inesmas, levantadas durante a coleta de dados. Deveria ser organizado um arquivo na Unidade Sanitária onde serão catologadas as fichas de identificação (Anexo I).

Estas fichas seriam manuseadas pela enfermeira, da Unidade, responsável pelo controle das parteiras. A cada comparecimento a enfermeira anotaria a data, o número de partos realizados, o número de encaminhamentos, o material solicitado e observações, tais como: tenía discutido na reuriāo, orientação individual, problemas ocorridos durante os partos e outros. O preenchimento correto e contínuo das fichas iria 
TAVARES, C.M.A. - Planejamento para a participação de alunos dos últimos periodos do ciclo profissional de enfermagem na identificaçāo e treinamento de parteiras leigas de ums comunidade. Rev. Bras. Enf.; DF, 32 : 89-120, 1979.

servir para a observação da qualidade da assistência prestada à comunidade

\subsection{2 - Organização dos Grupos}

Deverianı ser organizados grupos de no máximo 10 parteiras para cada instrutor, para que através de reuniões de discussão, demonstrações e palestras sejam ensinadas às parteiras leigas, téc- nicas simples para melhorar a assistência ao parte.

Os cursus teriam lugar na Unidade Sanitária, na sala de parto de uma maternidade e em domicilios da comunidade.

De acordo com a área de atendimento da parteira e a divisão do ano letivo seriam formados os grupos.

\begin{tabular}{l|c|c}
\hline \multirow{2}{*}{ Local } & \multicolumn{2}{|c}{ SEMESTRE } \\
\cline { 2 - 3 } Frea 1 & Te & 2 G \\
\hline Area 2 & Grupo A & Grupo D \\
\hline Frea 3 & Grupo B & Grupo E \\
\hline
\end{tabular}

\subsection{3 - Conteúdo do Programa}

\subsubsection{1 - Título do curso}

Orientação para Parteiras Leigas

\subsubsection{2 - Objetivos}

- Desenvolver técnicas simples e discuti-las à luz da experiência das parteiras leigas para que as mesmas possam dar melhor assistência ao parto em domicilios.

- Conscientizar a parteira sobre seu papel em relação à assistência médico-sanitária adequada, bem como sua participação na redução da morbidade e mortalidade materna e infantil.

- Promover seu entrosamento com a unidade sanitária para contro. le e orientação contínua de suas atividades, apoiando-se em um sistema de autenticidade e confiança no trabalho integrado.

- Reconhecer e apoiar a posiçāo de líder que a parteira ocupa dentro da comunidade, para a promoção da saúde, sobretudo de gestantes e crianças.

\subsubsection{3 - Carga Horária}

20 horas. 
TAVARES, C.M.A. - Planejamento para a participaçāo de alunos dos últimos periodos do ciclo profissional de enfermagem na identificaçāo e treinamento de parteiras leigas de uma comunidade. Rev. Bras. Enf.; DF, 32 : 89-120, 1979.

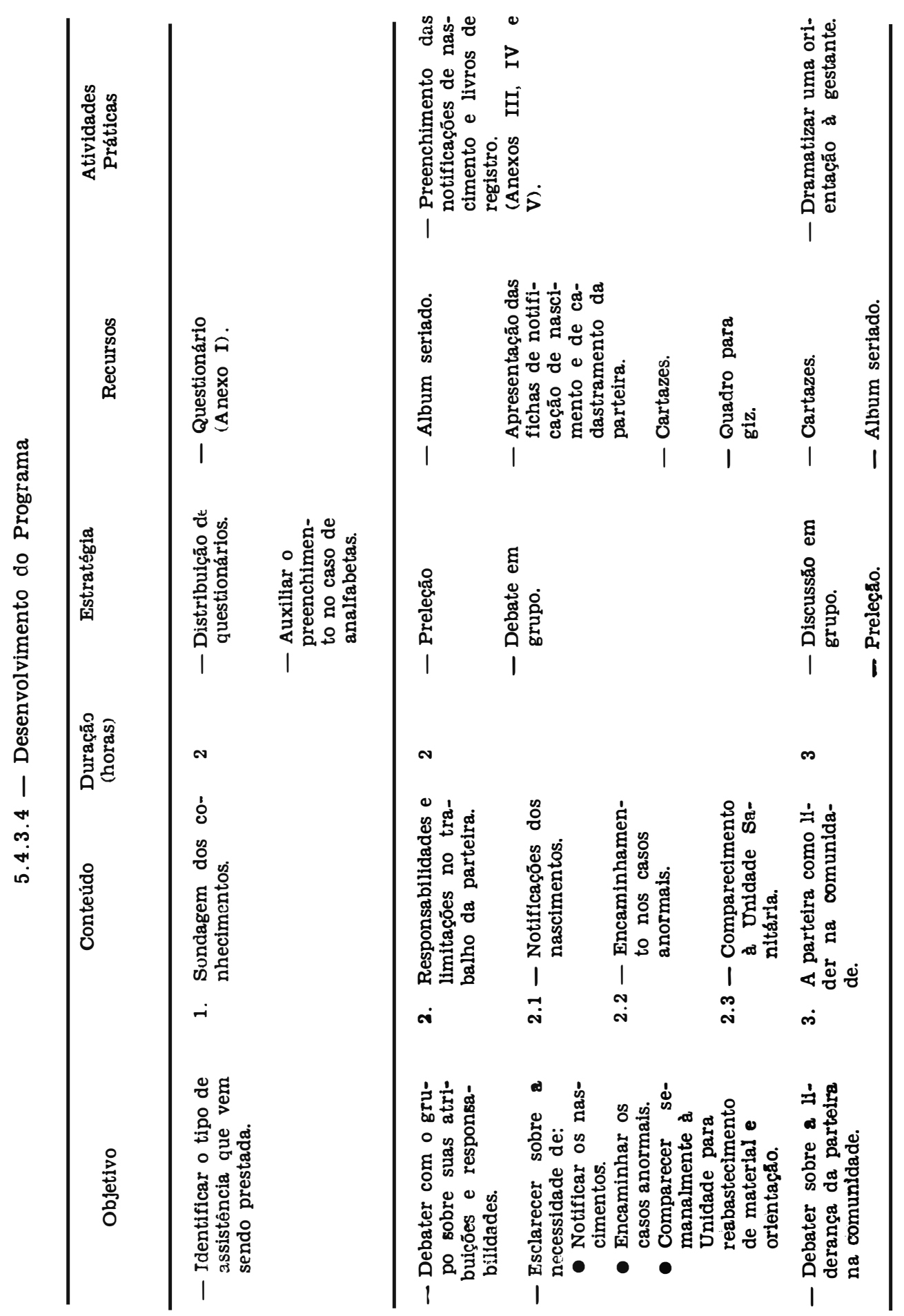




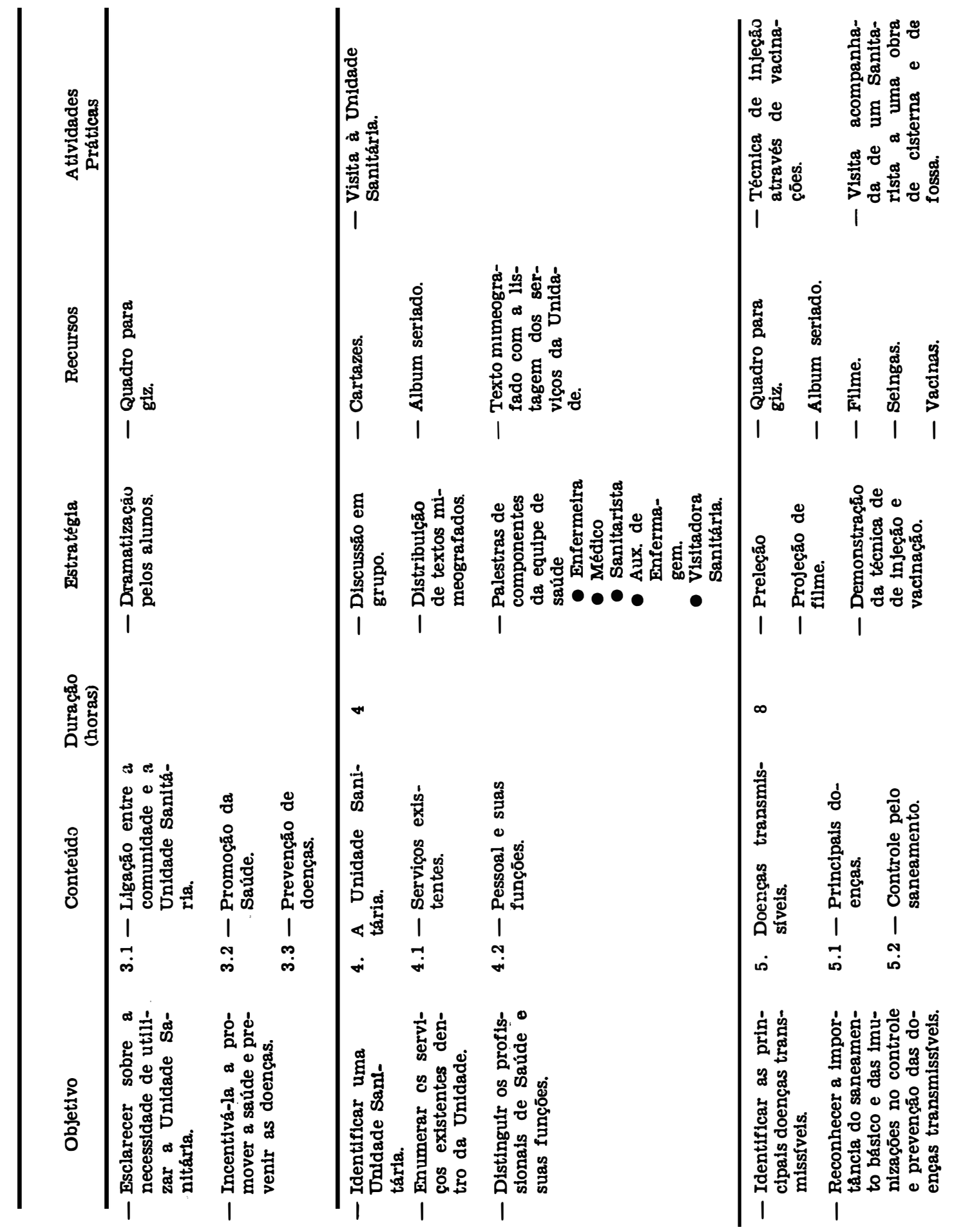




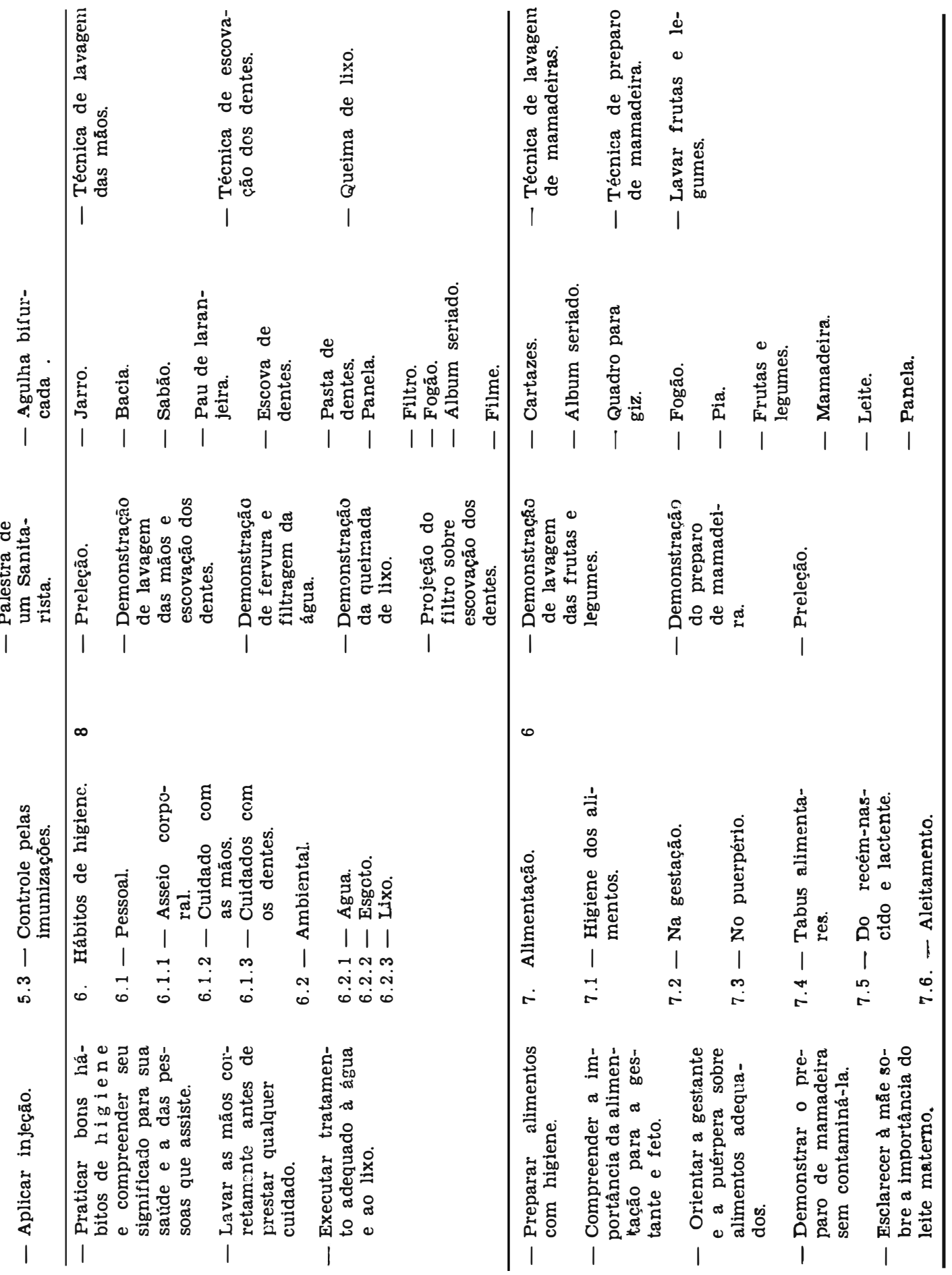




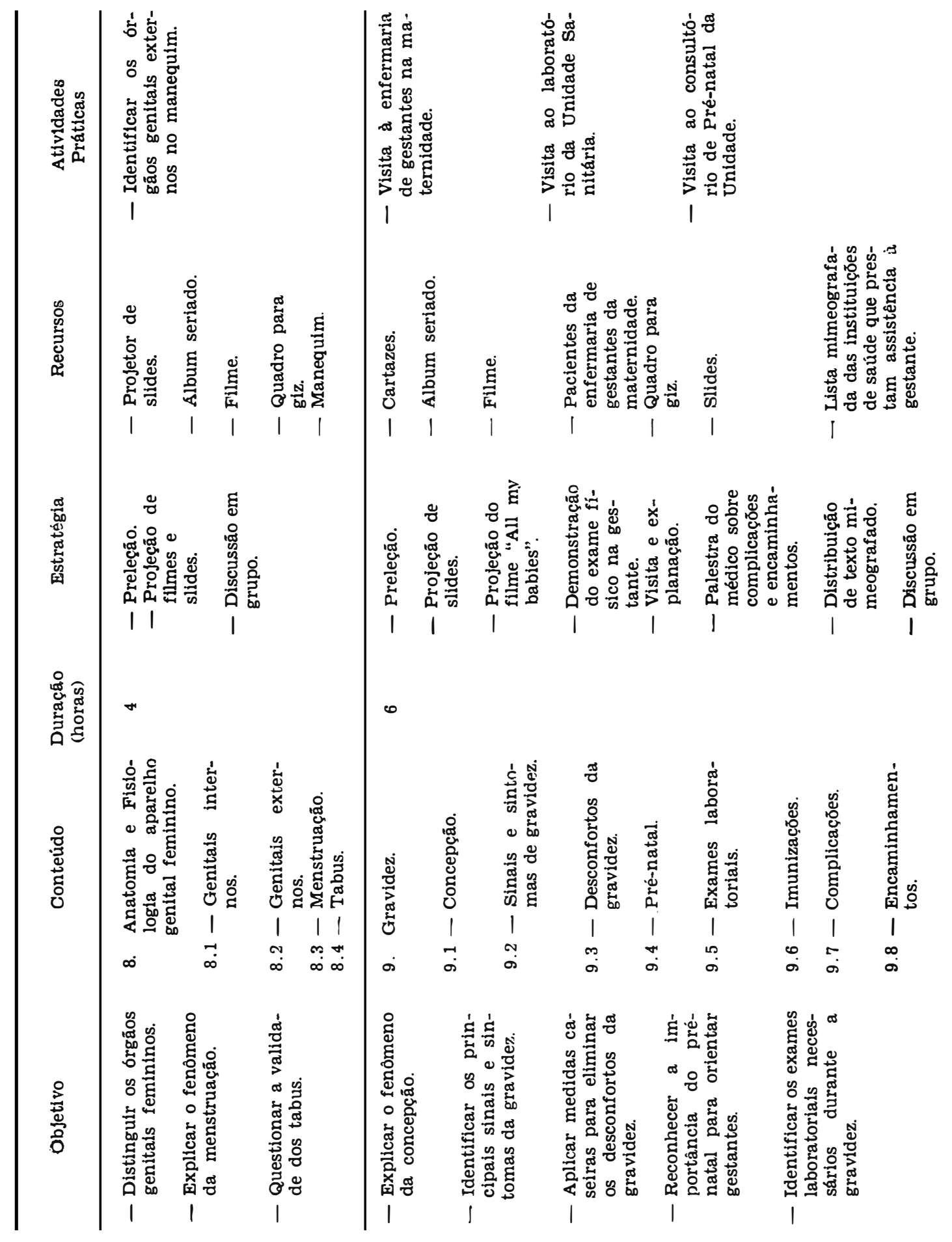




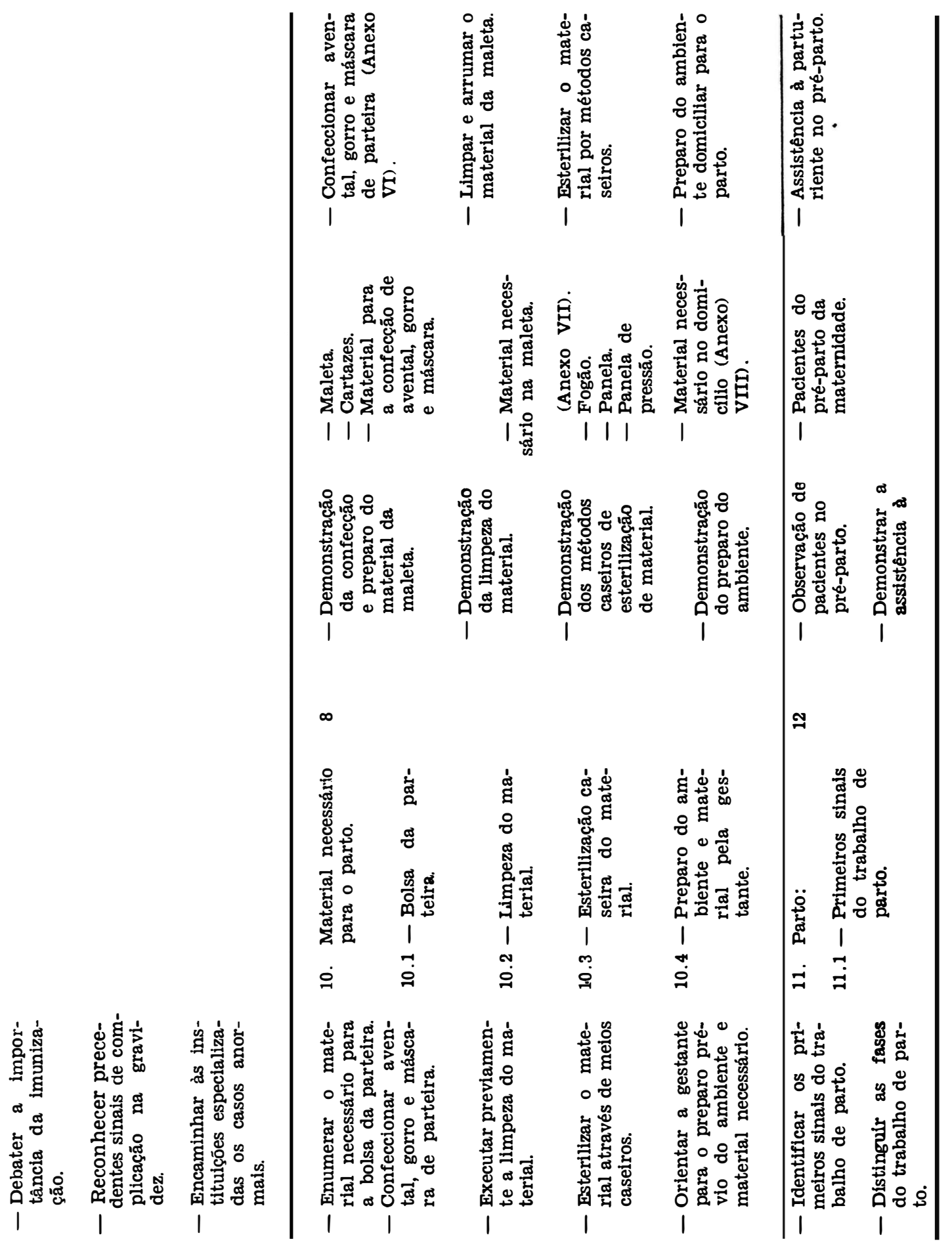




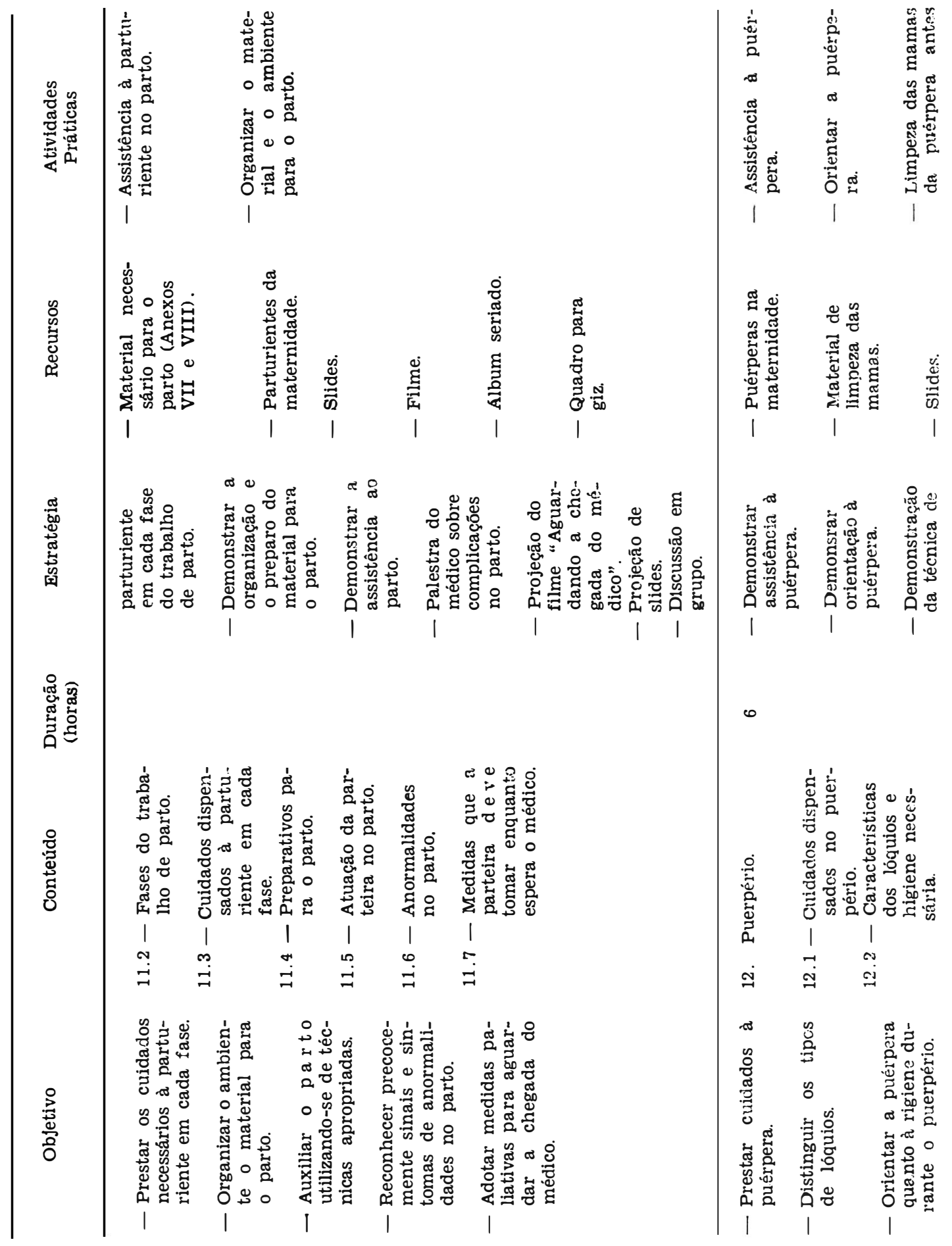




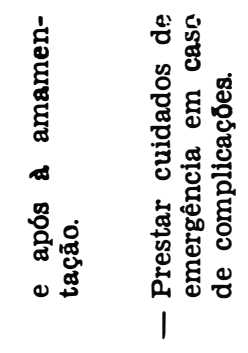

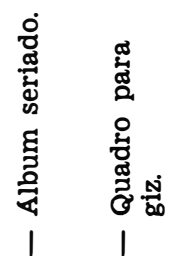

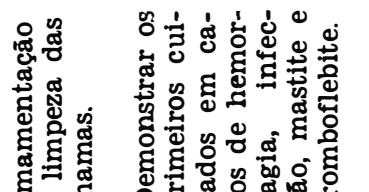

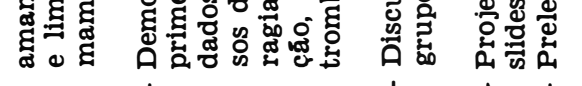

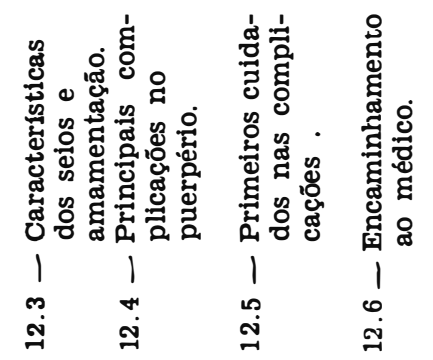

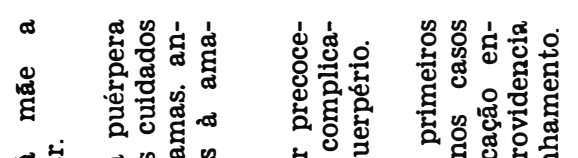

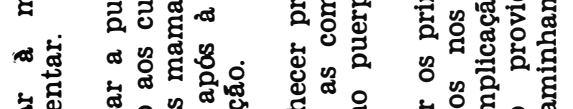

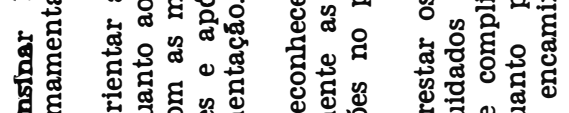

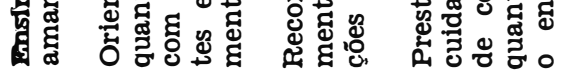

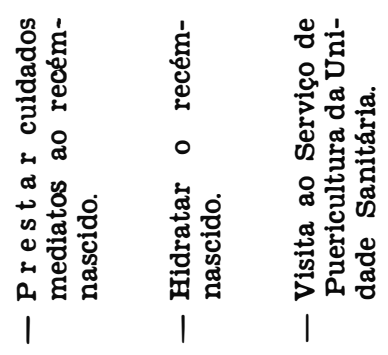

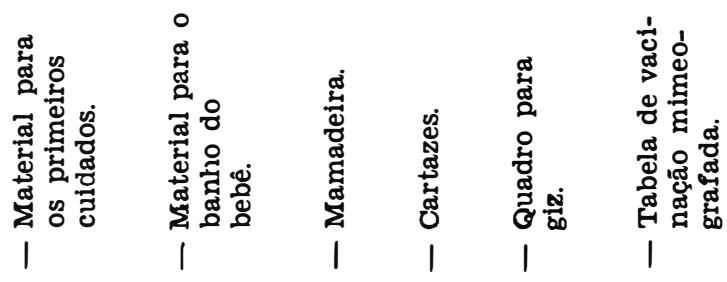

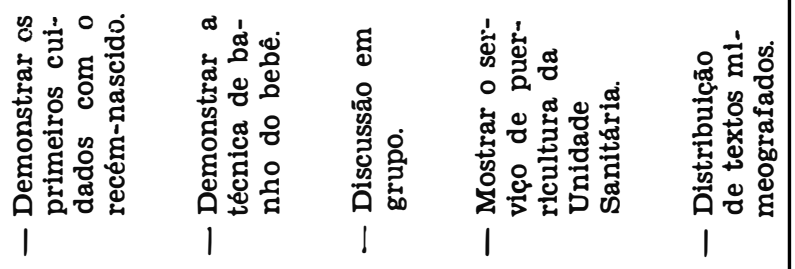
$\infty$

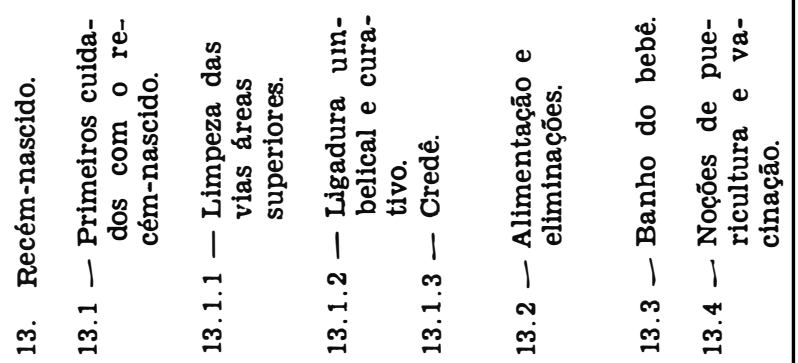

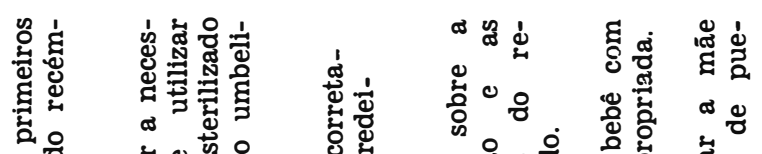
苔。

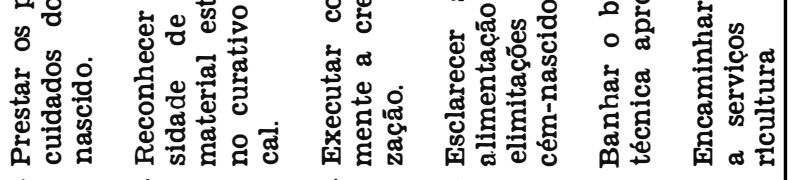




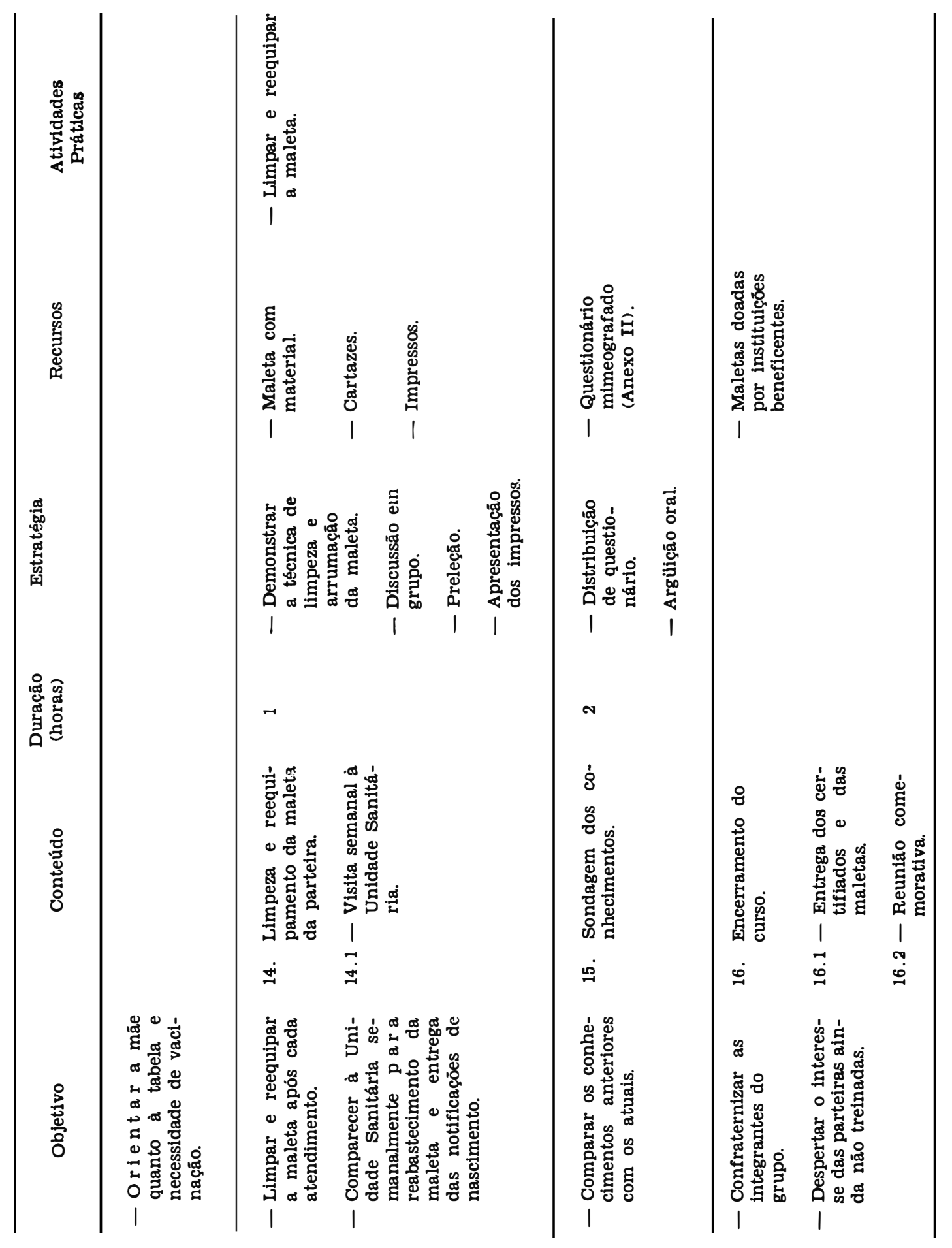


TAVARES, C.M.A. - Planejamento para a participação de alunos dos últimos periodos do ciclo profissional de enfermagem na identificaçāo e treinamento de parteiras leigas de uma comunidade. Rev. Bras. Enf.; DF, $32: 89-120,1879$.

\subsubsection{5 - Avaliação}

Seria aplicado no início do curso um questionário para sondagem de conhecimentos e atividades desenvolvidas.

No transcurso das aulas seriam observadas: a participação nos debates de grupo, a assiduidade e o desempenho nas técnicas.

Ao final do curso seria aplicado um questionário de sondagem sobre os conhecimentos adquiridos e as mudanças de comportamento sentidas e demonstradas.

\subsection{4 - Estratégia de Supervisão das Parteiras}

Tão importante quanto o treinamento é a supervisão continuada, através de apoio e controle no trabalho das parteiras. Para que ela nāo volte ao padrão do antigo trabalho é necessária a sua vinculação à Unidade Sanitária e supervisão das visitadoras no seu local de prestação de serviços.

Após o treinamento seriam discutidas e propostas algumas atribuições da parteira, tais como as que se seguem:

\subsubsection{1 - Parteira}

- Assistir partos em domicílio dentro dos ensinamentos e técnicas recebidos durante o curso:

- Comparecer semanalmente para reabastecer a maleta de material (curativo esterilizado, nitrato de prata, mertiolate, fichas) e entregar fichas de notificação de nascimento:

- Comunicar à enfermeira da Unidade Sanitária ocorrência de complicaçōes e os encaminhamentos feitos;
- Comparecer mensalmente à reuniāo da Unidade Sanitária, para limpeza e renovação do material da maleta e complementar conhecimentos através de orientações;

- Encaminhar gestantes e crianças à Unidade Sanitária para acompanhamento médico-sanitário;

- Promover a saúde, através da divulgação na comunidade, de informações sobre saneamento básico, prevenção de doenças e instituições de saúde existentes na área.

- Indicar as novas parteiras leigas das comunidades próximas.

- Participar do treinamento feito pelas Unidades Sanitárias, quer como aluna, quer como auxiliar de treinamento de outras.

\subsubsection{2 - Enfermeira da Unidade}

- Distribuir para as parteiras medicamentos e material esterilizado, semanalmente ou quando necessário;

- Organizar mensalmente reunióes, para limpeza e reabastecimento da maleta e, para orientação através de palestras;

- Analisar individualmente ou em grupo os casos elogiáveis ou reprováveis;

- Receber fichas de notificações dos partos assistidos pelas parteiras;

- Orientar visitadoras sanitárias em relação às visitas domiciliares às puérperas e recém-nascidos cuidados pelas parteiras;

- Atualizar anualmente as fichas de saúde de cada parteira;

- Atualizar o mapa de distribuição de parteiras controladas na área: 
TAVARES, C.M.A. - Planejamento para a participação de alunos dos últimos periodos do ciclo profissional de enfermagem na identificação e treinamento de parteiras leigas de uma comunidade. Rev. Bras. Enf.; DF, 32:89-120, $15 \cdot 79$.

- Descobrir novas parteiras leigas:

- Promover o treinamento das parteiras descobertas.

\section{5 - Quinta Etapa - Implemen- tação do Programa}

\subsection{1 - Matrícula}

Seriam matriculadas no curso de treinamento, as parteiras leigas atuan. tes na área, identificadas na análise da comunidade.

No ato da matrícula seria preenchida a ficha de cadastramento, relativas e seriam dadas as orientações, relativas ao curso, para a parteira.

\subsection{2 - Freqüência}

Receberiam certificados de conclusão as parteiras que freqüentassem $\mathbf{8 5 \%}$ do curso. As que forem eliminadas por falta, estariam automaticamente matriculadas na próxima turma.

\subsection{3 - Local do Treinamento}

As aulas seriam realizadas na Unidade Sanitária. No caso de impossibilidade deveria escolher-se um local adequado ao propósito, dentro da própria comunidade onde as mesmas residem.

\subsection{4 - Locais e Estágio}

- Unidade Sanitária

- Maternidade

- Domicílios (seriam indicados pelas parteiras).

\subsection{5 - Grupos}

Seriam formados grupos de no máximo dez parteiras.

\subsection{6 - Duração e Carga Horária do Curso}

Os cursos teriam duração de um mês e meio, com carga horária mínima:

Teórica $\quad-20$ horas
Teórico-prático -60 horas.

\subsection{7 - Exame de Saúde}

As parteiras fariam os seguintes exames de saúde, na Unidade Sanitária:

- Abreugrafia e baciloscópia

- Parasitológico

- Sorologia para Lues

- Dermatológico.

Obs.: Só freqüentariam a primeira turma do curso as que fossem consideradas aptas no exame de saúde. As que assim nāo o fossem, fariam tratamento de saúde e esta.riam automaticamente admitidas na próxima turma.

\subsection{8 - Corpo Docente}

As aulas seriam ministradas po: alunos de enfermagem dos últimos períodos do curso de graduação e integrantes da equipe da Unidade Sanitária.

\subsection{9 - Certificado de Conclusão}

Seria concedido Certificado de Conclusão, às parteiras que alcançassem aproveitamento mínimo de $70 \%$ e a freqüência já estipulada. As que não alrançassem esse nivel, estariam automa.. ticamente matriculadas no próximo curso. 
TAVARES, C.M.A. - Planejamento para a participaçāo de alunos dos últimos perfodos do ciclo profissional de enfermagem na identificaçāo e treinamento de parteiras leigas de uma comunidade. Rev. Bras. Enf.; DF, $32: 89-120,1979$.

\subsubsection{0 - Controle e Supervisão após o Curso}

Seria realizado através de:

- Comparecimento s e m a n a l da parteira à Unidade Sanitária. onde serāo entregues as notificações de nascimento;

- Comparecimento mensal à Unidade Sanitária para reuniāo de atualização;

- Visitas domiciliares às clientes atendidas.

\subsubsection{1 - Início das Atividades}

\section{Anexo $\mathrm{X}$}

\subsubsection{2 - Avaliação do Programa}

Seria realizada nos meses de janeiro e fevereiro, coincidindo com as férias escolares.

O instrumento de avaliação do programa seria montado pela equipe em tempo hábil, considerando os objetivos do programa.

ANEXO I - Questionário de Sondagem Preliminar

NOME:

IDADE:

\section{GRAU DE INSTRUÇÃO:}

LOCALIDADE QUE ATENDE:

1. Quantos partos fez no ano passado? no mês passado?

2. Encaminha as gestantes que atende, à Unidade Sanitária?

3. Costuma acompanhar suas gestantes durante a gravidez ou só é chamada na hora do parto?

4 Que preparativos recomenda que a gestante faça para o parto?

5. Que material costuma levar para assistir ao parto?

6. Onde realiza os partos (cama, esteira, rede, cadeira)?

7. Para assistir ao parto você lava as mãos? Quando?

8. Faz limpeza da parturiente antes do parto Depois? 
TAVARFS, C.M.A. - Planejamento para a participaçāo de alunos dos últimos períodos do ciclo profissional de enfermagem na identificaçāo e treinamento de parteiras leigas de uma comunidade. Rev. Bras. Enf.; DF, 32:89-120, 1979.

9. Entre as pacientes que assistiu houve algum parto anormal?

Qual foi a anormalidade?

O que você fez?

10. Já fez algum parto em que a criança nasceu morta?

De que morreu?

11. Como sabe a hora em que a criança vai nascer?

12. Quando ensina a parturiente a fazer força?

13. O que costuma fazer quando o parto é demorado?

14. O que faz quando aparece a cabeça da criança?

15. Quando corta o cordão umbilical?

Como e com que corta?

Como llga?

16. Quando limpa a criança?

Como limpa?

17. Ajuda a paciente a expulsar a placenta?

Como?

Quando?

18. O que faz quando a paciente perde multo sangue?

19. O que você dá à criança para tomar logo depois que nasce?

Por que?

20. Quando sobe o primeiro leite?

O que faz com ele? Por que? 
TAVARES, C.M.A. - Planejamento para a participação de alunos dos últimos períodos do ciclo profissional de enfermagem na identificaçāo e treinamento de parteiras leigas de uma comunidade. Rev. Bras. Enf;; DF, $32: 89-120,1979$.

21. Quanto tempo depois de nascida, pōe a criança para mamar?

22. Acha que alguns alimentos podem fazer mal à gestante? Quais?

A puérpera? Quais?

$\mathrm{O}$ que podem causar?

23. Por quantos dias você presta cuidados à mãe e à criança?

ANEXO II - Questionário de Sondagem Posterior

NOME:

GRAU DE INSTRUÇAO:

LOCALIDADE QUE ATENDE:

DATA DO CURSO: INFCIO

TERMINO

GRUPO: INSTRUTOR:

1. Os assuntos abordados durante o curso já eram de seu conhecimento?

2. Quais eram desconhecidos?

3. Que tipo de encaminhamento fará para uma gestante?

4. A gestante deve ser acompanhada pela parteira? Quando?

5. Que preparativos recomendaria à gestante para o parto?

6. Qual o material necessário para o parto?

7. Como deve ser o ambiente onde se realizará o parto?

8. Quando devem ser lavadas as mãos?

9. Descreva os passos da assistência a o parto.

10. Quais as orientações que você daria a uma gestante?

11. E a uma puérpera?

12. Quais as providências que tomaria em caso de complicação? 
TAVARES, C.M.A. - Planejamento para a participação de alunos dos últimos períodos do ciclo profissional de enfermagem na identificaçāo e treinamento de parteiras leigas de uma comunidade. Rev. Bras. Enf.; DF, 32:89-120, 1979.

ANEXO III - Cadastramento da Parteira na Unidade Sanitária UNIDADE SANITARIA

NOME DA PARTEIRA:

N.':

ENDEREÇO:

PONTO DE REFERENCIA:

GRAU DE INSTRUÇÃO:

EXAME DE SAÚDE:

DATA:

TREINAMENTO: INfCIO

TÉRMINO

GRAU DE APROVEITAMENTO DURANTE O CURSO:

ENFERMEIRA RESPONSAVEL:

DATA:

OBSERVAC̣ŌES:

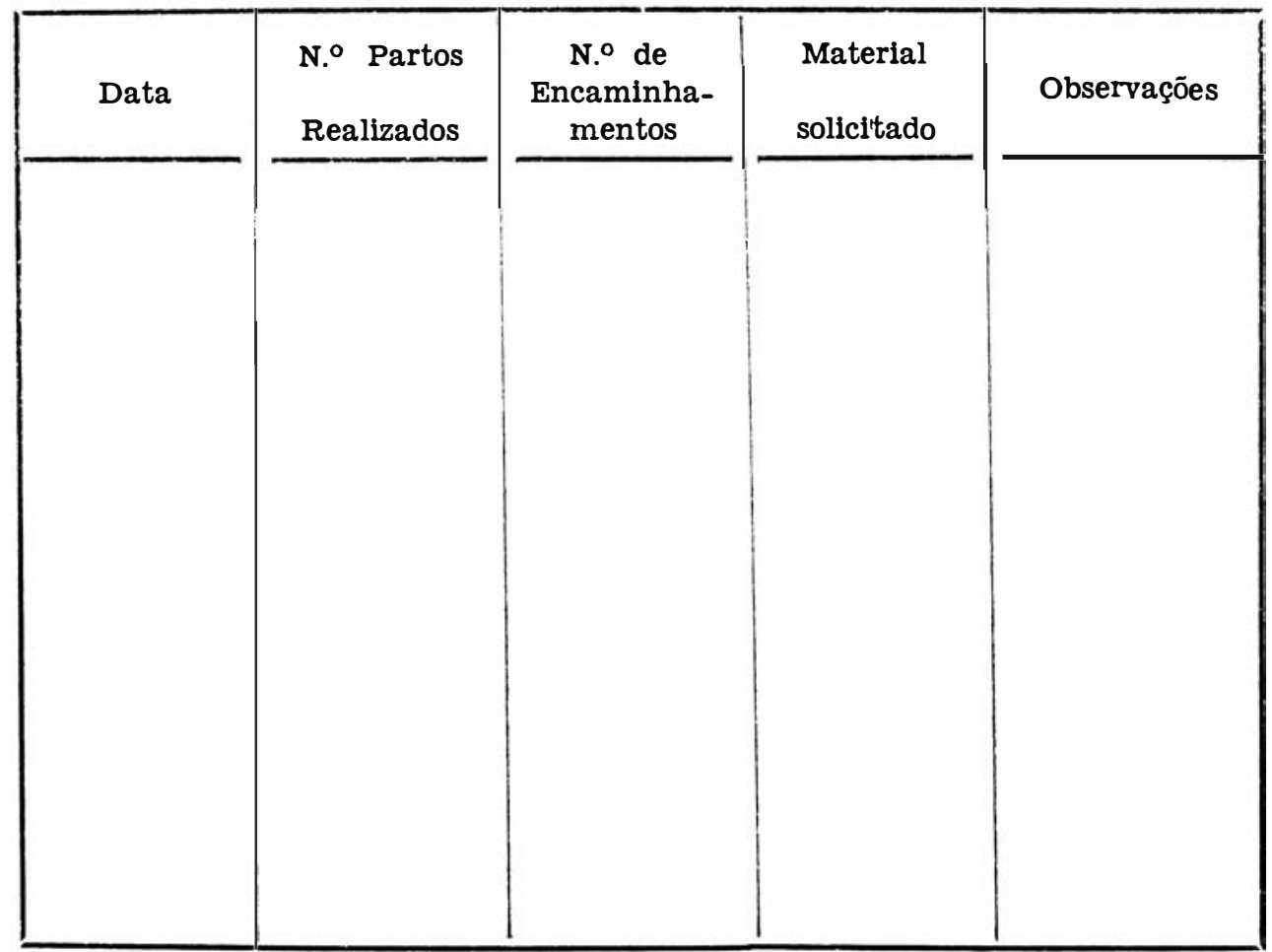


TAVARES, C.M.A. - Planejamento para a participaçāo de alunos dos últimos periodos do ciclo profissional de enfermagem na identificaçāo e treinamento de parteiras leigas de uma comunidade. Rev. Bras. Enf.; DF, 32 : 89-120, 1979.

ANEXO IV - Notificação de Nascimento para a Unidade Sanitária

\section{Unidade Sanitária}

NOTIFICAÇĀO DE NASCLMENTO

deu à luz a

ưna criança do sexo com tempo de

gestação de meses, no dia

às horas.

Peso

gramas. Estatura

cm.

Endereço do domicílio:

Parteira:

N. ${ }^{\circ}:$

COMPLICAÇÕES:

PROVIDENCIAS TOMADAS:

OBSERVAÇÕES: 
TAVARFS, C.M.A. - Planejamento para a participaçāo de alunos dos últimos periodos do ciclo profissional de enfermagem na identificaçāo e treinamento de parteiras leigas de uma comunidade. Rev. Bras. Enf.; DF, 32 : 89-120, 1579.

ANEXO V - Comprovante do Nascimento para a Mãe

\section{UNIDADE SANITÁRIA}

NOME DA CRIANÇA:

FILHO DE: MAE:

PAI:

DATA DE NACIMENTO:

HORA:

PESO:

ESTATURA:

CONDIÇŌES AO NASCER:

ENDEREÇO:

MUNICÍPIO:

ESTADO:

PARTFIRA :

\begin{tabular}{|c|c|c|}
\hline IMUNIZAÇŌES & DATA & OBSERVAÇŌES \\
\hline \multicolumn{3}{|l|}{$\mathrm{BCG}$} \\
\hline \multicolumn{3}{|l|}{ Sabln } \\
\hline \multicolumn{3}{|l|}{ Triplice } \\
\hline \multicolumn{3}{|l|}{ Antivariólica } \\
\hline \multicolumn{3}{|l|}{ Sarampo } \\
\hline \multicolumn{3}{|l|}{ Antitetânica } \\
\hline Antimeningite & & \\
\hline
\end{tabular}


TAVARES, C.M.A. - Planejamento para a participaçāo de alunos dos últimos períodos do ciclo profissional de enfermagem na identificaçāo e treinamento de parteiras leigas de uma comunidade. Rev. Bras. Enf.; DF, 32 : 89-120, 1979.

ANEXO VI - Livro de Registros da Parteira

UNIDADE SANITÁRIA

NOME DA PARTEIRA:

N. ${ }^{\circ}$ :

ENDEREÇO:

MUNICfPIO:

ESTADO:

PARTOS ATENDIDOS

NOME DA PARTURIENTE:

ENDEREC̣O:

PONTO DE REFERENCIA:

MUNICIPIO:

ESTADO:

CONDIÇOES DO PARTO:

COMPLICAÇסES:

PROVIDENCIAS TOMADAS:

CONDIÇOESS DA CRIANÇA AO NASCER:

DATA E HORA DE NASCIMENTO:

PESO:

ESTATURA:

OBSERVAÇOEES: 
TAVARES, C.M.A. - Planejamento para a participação de alunos dos últimos periodos do ciclo profissional de enfermagem na identificaçåo e treinamento de parteiras leigas de una comunidade. Rev. Bras. Enf.; DF, 32 : 89-120, 1979.

ANEXO VII - Vestuário da Parteira
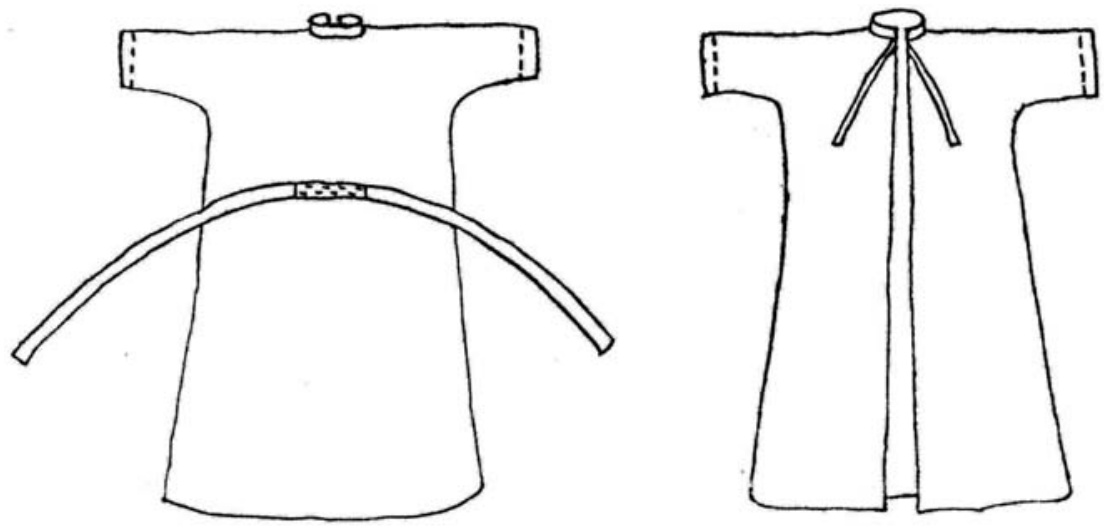

1. Avental

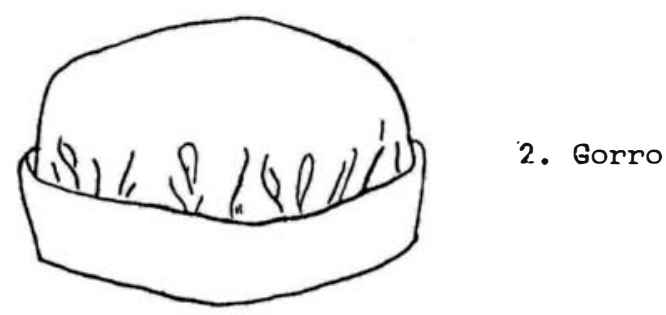

3. Máscara

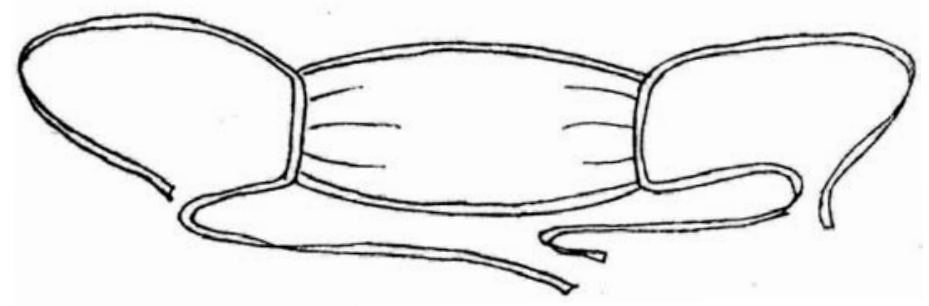


TAVARES, C.M.A. - Planejamento para a participação de alunos dos últimos periodos do ciclo profissional de enfermagem na identificaçāo e treinamento de parteiras leigas de uma comunidade. Rev. Bras. Enf.; DF, $32: 89-120,15.79$.

\section{ANEXO VIII \\ Maleta da Parteira}

A maleta deverá ter armação forte, feita de modo a permitir fechar-se bem ou conservar-se aberta de modo que os objetos sejam retirados com facilidade. $E$ provida de um gorro de pano barato, que pode ser tirado para lavar. $O$ gorro é um saco retangular que se abre e fecha por meio de um cadarço duplo. Ao se abrir a maleta, pode ser dobrado sobre sua beirada para protegê-la ou pode permanecer fechado para proteger seu conteúdo.

O material contido na maleta deverá ser:

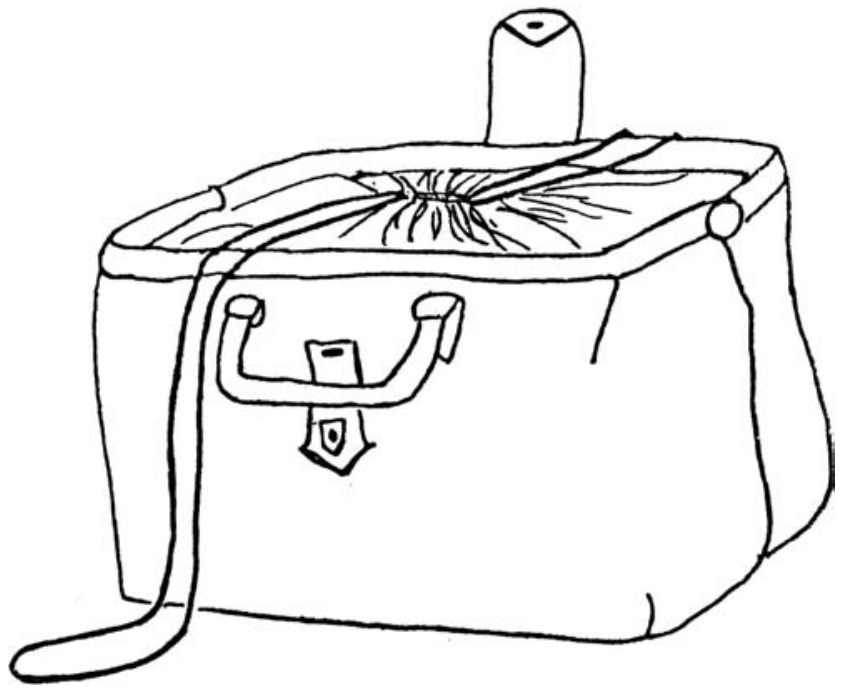

Maleta de Parteira

- 2 gorros plásticos de aproximada- -1 livro de registros e impressos de mente $80 \times 80 \mathrm{~cm}$. notificação de nascimento.

-. 1 gorro plástico de aproximadamente $50 \times 50 \mathrm{~cm}$.

- 1 tesoura de ponta redonda.

-1 vidro de conta-gotas com nitrato de prata a $1 \%$.

- 1 envelope plástico, contendo:

1 escova de unhas.

- 1 vidro com mertiolate ou mercúrio.

2 toalhas de mão.

- 1 envelope plástico, contendo:

1 avental.

1 gorro.

1 máscara.

- 1 saco plástico com algodāo.

- 1 saco de papel.

- 1 saboneteira com sabão.

- 1 balança de mão.

- 1 vidro de álcool.

- 2 pacotes de curativo umbilical, contendo:

- 1 gaze dobrada, com uma ponta gendada.

- 1 palito com ponta de algodão ou cotonete.

- 3 cordōes de $30 \mathrm{~cm}$ (linha Ursa n. 0 , ou similar).

- pedaços de gaze IV.

- 1 pacote de curativo, contendo:

1 gaze gendada. 
TAVARES, C.M.A. - Planejamento para a participação de alunos dos últimos periodos do ciclo profissional de enfermagem na identificação e treinamento de parteiras leigas de uma comunidade. Rev. Bras. Enf.; DF, 32: 89-120, 1579.

1 palito ou cotonete.

- 1 bandeja ou bacia pequena.

- 1 sonda retal.

-1 funil.

- 1 tubo de borracha de aproximadamente $80 \mathrm{~cm}$.

-1 intermediário de vidro.

- 1 recipiente para solução.

- papel higiênico.

- fita métrica.

- termômetro.

-2 seringas.

-4 agulhas.

- caneta.

ANEXO IX

Material Necessário no Domicílio

Convém que a gestante prepare desde o início do 8. ${ }^{\circ}$ mês, o material necessário para o hora do parto.

Compete à parteira dar à mãe direções minuciosas para a preparação do quarto para o parto, cabendo à família a responsabilidade disso.

Medidas a serem tomadas:

- Limpeza minuciosa do quarto, principalmente da cama;

- A cama deve ficar para o centro do quarto com os pés expostos à melhor luz;

- Preparar a cama da criança;

- Providenciar o material necessário, que é:

- 2 paninhos para higiene

- 2 toalhas

- 4 fronhas

- 4 lençóis
- 2 camisolas

- 1 cobertor

- 1 par de meias brancas

- 1 dúzia de panos higiênicos ou

2 caixas de modess.

- 1 pacote de algodão

- 200 folhas de jornais

- 1 chaleira

- 2 baldes

- 1 caçarola grande com tampa

- 1 jarro de água

- sabão de côco

- tesoura comum

- 1 rolo de papel higiênico fe.. chado

- 1 urinol

- roupinhas da criança

- utensílios da criança.

\section{RECOMENDAÇÓES}

- Sejam implantados programas como este para elevação do nível de saúde da população;

- As Universidades modifiquem o enfoque, no ensino de enfermagem, de assistência individualizada para comunitária;

- Os alunos dentro das suas atividades práticas, interem-se com a realidade da comunidade;

- Haja interação entre as açōes da Comunidade, Universidade, Unidades Hospitalares e Unidades de Saúde Pública;

- As parteiras sejam encaradas como agentes de saúde dentro da Comunidade. 
TAVARES, C.M.A. - Planejamento para a participaçåo de alunos dos últimos periodos do ciclo profissional de enfermagem na identificaçāo e treinamento de parteíras Teigas de uma comunidade. Rev. Bras. Enf.; DF, 32 : 89-120, 1979.

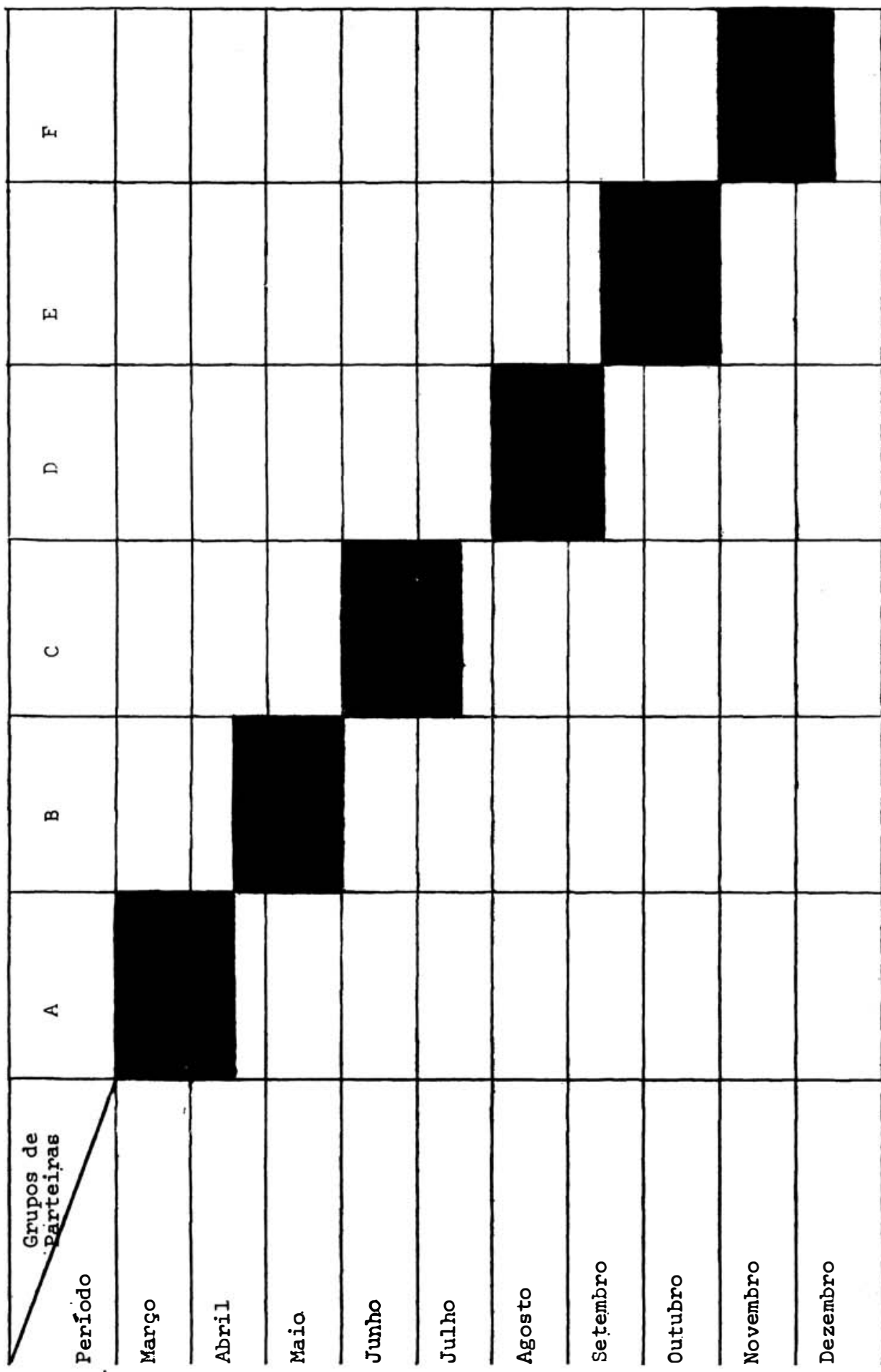


TAVARES, C.M.A. - Planejamento para a participação de alunos dos últimos períodos do ciclo profissional de enfermagem na identificação e treinamento de parteiras leigas de uma comunidade. Rev. Bras. Enf.; DF, $32: 89-120,19.79$.

\section{BIBLIOGRAFIA}

1. BRYANT, John H. - Los Agentes de Solud de la Comunidad: un Vínculo entre las Comunidades y los Sistemas de Atención Sanitária. In: Crónica de la OMS. Washington, OMS, 32:157-161, 1978.

2. CFERUBIN, Niversindo A. - Fundamentos da Administraçāo Hospitalar. São Paulo, Grafikor Editora, 1976, V. 1, 238 pág.

3. FREDDI, Wanda Escobar S. - A enfermeira obstétrica no contexto brasileiro. In: Enfermagem em Novas Limensōes, São Paulo, 3(5): 283-8, 1977.

4. FUNDAÇAOO PROJETO RONDON O Guia da Parteira Leiga. Goiânia, Fundação Projeto Rondon de Goiás, s.d., 56 pág.

5. IBGE - Anuário Estatistico do Brasil. Rio de Janeiro, 1977, V. 38, 1.843 pág.

6. JIRON, M. F. - Parto Domiciliar. In: Revista Paulista de Hospitais. São Paulo, 16(1) :51-5, Jan. 1968.

7. JONES, Anita M. - Manual para o Ensino de Parteiras. Washington, Empresa do Governo dos Estados Unidos, 1944, 140 pág.

8. MINISTÉRIO DA EDUCAÇAO E CULTURA - Indicadores de Qualidade para Cursos de Graduaçāo em Enfermagem. Brasilia, DAU/GSS, s. d., 5 pág.

9. MINISTERIO DA SAÚDE - Manual para Programa de Penetraçāo Rural. Rio de Janeiro, Divisão Nacional de Organização Sanitária, 1974, p. 121-131.

10. MINISTÉRIO DA SAÚDE - Politica de Saúde Materno-Infantil. Brasilia, M.S., S.d., 23 p.

11. MINISTÉRIO DA SAÚDE - Programe Nacional de Saúde Materno-Infantil. Brasília, Coordenação de Proteção Materno-Infantil. 1975, 19 p.
12. NETTO, Malvina O. R. e EGRY, Emiko Y. - Curso de Treinamento de Curiosas Marabá - Pará. In: Enfermagem em Novas Dimensões. 2(3):145-8, 1976.

13. NóbReGA, Maria Rosário S. - Descoberta, Treinamento e Controle de Parteiras Curiosas - uma necessidade no Brasil. In: Revista Brasileira de Enfermagem. (1 e 2) 80-96, Jan/Jun 1970.

14. ORGANIZACIÓN MUNDIAL DE LA SALUD - Atención Primária de Salud. Switzerland, OMS, 1978, $55 \mathrm{p}$.

15. ORGANIZACIÓN MUNDIAL DE LA SALUD - Relación entre Los Agentes de Salud de La Comunidad, Los Serviços Sanitarios y la Própria Comunidad. In: Crónica de la OMS, 32:162-6, 1978.

16. ORGANIZACION PANAMERICANA DE LA SALUD - El Papel de La Enfermeira en La Atención Primária de Salud. Washington, Oficina Sanitária Panamericana, 1977, $16 \mathrm{p}$.

17. ORGANIZACIÓN PANAMERICANA DE LA SALUD - IV Reunião Especial de Ministros de Salud de Las Americas. Washington, Oficina Sanitária Panamericana, 1978, $53 \mathrm{p}$.

18. PARETA, J.M.R. Et Alii - Saude da Comunidade: Temas de Medicina Preventiva e Social. São Paulo Editora Mc Graw-Hill do Brasil, 1976, 295 p..

19. ROBAYO, Jorge C. - Situaciones de Cobertura, Niveles de Atención $Y$ Atención Primária. In: Boletim de La Oficina Sanitária Panamericana. 82(6) :478-492, 1977.

20. SECRETARIA DE SAÚDE DO CEARA - Manual Para Orientadores de Saúde e Saneamento. Fortaleza. Programa de Interiorização das Açōes de Saúde e Saneamento PIASS, 1977, V. 1.

21. SESP - Programa de Orientaçāo Para Parteiras Curiosas. Rio de Janelro, Fundação SESP, 1972, 50 p. 